\title{
AVALIAÇÃO DA PERCEPÇÃO MÉDICA ACERCA DOS ASPECTOS ÉTICOS-LEGAIS ENVOLVIDOS NO EXERCÍCIO DA MEDICINA NO BRASIL
}

Marina de Souza Bastos Lino, Julianne Barroso Lima, Kataline de Souza Munhoz, Rafael de Oliveira Pena Neto, Evelyn Patrícia do Nascimento, Lilian Francisco Arantes de Souza, José de Oliveira Costa Filho

Universidade do Oeste Paulista - UNOESTE, Faculdade de Medicina Presidente Prudente, SP. E-mail: marynabastos@yahoo.com.br

\section{RESUMO}

A medicina defensiva é tida como um desvio da conduta médica considerada cientificamente padrão nos cuidados com o paciente, pois prioriza estratégias diagnósticas e terapêuticas, afim de se evitar demandas nos tribunais. Pensando em sua defesa, seria mais importante o médico conhecer as leis e os princípios éticos que regem a prática médica, pois em um processo éticodisciplinar ou judicial, são estes aspectos que serão avaliados. Neste contexto, este trabalho objetivou avaliar a percepção médica acerca dos aspectos éticos-legais envolvidos no exercício da medicina no Brasil, bem como correlacionar esse dado com as variáveis sexo, idade, graduação em instituição de ensino superior pública ou privada e tempo de exercício da profissão. Trata-se de um estudo transversal descritivo, aprovado pelo Comitê de Ética em Pesquisa sob no CAAE 55113616.0.0000.5515, realizado a partir de questionário respondido por 150 médicos atuantes no Hospital Regional de Presidente Prudente, São Paulo. A amostra foi constituída em sua maioria por médicos com idade $\leq 30$ anos, graduados em instituição privada e com $\leq 2$ anos de exercício da medicina. De maneira geral, os resultados evidenciaram deficiências importantes na percepção dos médicos estudados sobre os temas ética e responsabilidade médica.

Palavras-chave: Ética médica, Responsabilidade civil, Erro médico, Medicina defensiva.

\section{EVALUATION OF MEDICAL PERCEPTION ON ETHICAL-LEGAL ASPECTS INVOLVED IN THE EXERCISE OF MEDICINE IN BRAZIL}

\begin{abstract}
Defensive medicine is considered a deviation from medical conduct considered scientifically standard in patient care, since it prioritizes diagnostic and therapeutic strategies in order to avoid lawsuits in court. Thinking about your defense, it would be more important for the doctor to know the laws and ethical principles that govern medical practice, because in an ethical-disciplinary or judicial process, these aspects will be evaluated. In this context, this study aimed to evaluate the medical perception about the ethical-legal aspects involved in the practice of medicine in Brazil, as well as to correlate this data with the variables gender, age, graduation in a public or private higher education institution and profession. This is a cross-sectional descriptive study, approved by the Research Ethics Committee under CAAE No. 55113616.0.0000.5515, based on a questionnaire answered by 150 physicians working at the Regional Hospital of Presidente Prudente, São Paulo. The sample consisted mostly of physicians aged $\leq 30$ years, graduated in a private institution and with $\leq 2$ years of medical practice. In general, the results evidenced important deficiencies in the perception of the doctors studied on the ethical and medical responsibility subjects.
\end{abstract}

Keywords: Medical ethics, damage liability, Medical errors, Defensive medicine. 


\section{INTRODUÇÃO}

Nos últimos anos o profissional médico tem sido um dos alvos preferidos da mídia, que aborda até mesmo com certo grau de sensacionalismo, os "erros médicos" evidenciados pelos pacientes, que buscam cada vez mais os tribunais almejando alguma reparação. No Brasil, não há estatísticas oficiais sobre a totalidade de processos envolvendo erros médicos, ao mesmo tempo, é notável o aumento de ações judiciais contra esses profissionais ${ }^{1}$. Estima-se hoje que exista cerca de dez mil processos tramitando nos tribunais contra médicos, em sua maioria arguindo responsabilidade civil do profissional ${ }^{2}$. Uma estatística divulgada pelo jornal "O Estado de São Paulo" apontou que entre 2010 e 2014 o Superior Tribunal de Justiça viu o número de processos por erro médico aumentar em $140 \%$. Para muitos existe uma atuante "indústria da indenização", o que explica a grande porcentagem de absolvições das acusações feitas, isso porque em boa parte dos casos o processo judicial é infundado, uma vez que mau resultado, ou até mesmo a morte, não significa que necessariamente houve um erro médico. Ainda pode-se acrescentar que muitas destas queixas sobre erro médico não são por conta de um efetivo erro, mas pela falta de um bom relacionamento entre médico e paciente.

Neste contexto, na década de 90 nos Estados Unidos surgiu a "medicina defensiva", definida como uma prática médica que prioriza condutas e estratégias diagnósticas e terapêuticas, afim de se evitar demandas nos tribunais. Implica em um desvio da conduta considerada cientificamente padrão nos cuidados com o paciente, por se caracterizar pela utilização exagerada de exames complementares, uso de procedimentos terapêuticos supostamente mais seguros, encaminhamento frequente de pacientes a outros especialistas e a recusa ao atendimento de pacientes graves e com maior potencial de complicações ${ }^{3}$.

De acordo com Ribas-Filho (2011), uma preocupação atual que as entidades médicas têm tido, diz respeito à medicina defensiva, que claramente faz aumentar os custos do exercício da profissão ${ }^{4}$. Dados da Associação Médica Americana estimam que os gastos com a medicina defensiva é responsável por $10 \%$ dos custos globais dos serviços médicos ${ }^{5}$. Isso não significa que o médico não deva solicitar exames, afinal esse é um recurso para fortalecer ou mesmo confirmar um diagnóstico, contudo, uma boa anamnese, seguida por um exame clínico detalhado, ainda é uma boa maneira de exercer a medicina. Além do que, a assertiva de que pedidos exagerados de exames podem se transformar em instrumento de defesa é controversa, pois com a socialização dos meios de informação, muitos pacientes possuem conhecimento suficiente que lhes confere juízo crítico sobre a conduta do médico, e ainda, em conflitos jurídicos, por se tratar de questões de alta indagação científica, os juízes devem se valer de peritos, os quais poderão demonstrar a desnecessidade de determinados exames para se obter o correto diagnóstico, sendo que o excesso pode ser entendido como imperícia, visto que muitos destes exames sofisticados e de complexa tecnologia podem causar danos ao paciente, o que confere culpa médica por ter sido desnecessário ${ }^{3}$.

A legislação brasileira é bastante justa em seu ordenamento jurídico no que se refere à responsabilidade penal e civil do médico, bem como o Código de Ética Médica (CEM) aplicado pelos Conselhos Regionais e Federal de Medicina, sendo que sua transgressão, especificamente das normas deontológicas, pode levar o infrator a receber penas legais ${ }^{6}$. Portanto, a proteção do médico não pode ser realizada por meio da prática indiscriminada da medicina defensiva. Pensando em sua defesa, seria mais o importante o médico conhecer as leis e os principais conceitos e princípios éticos que regem a prática médica, pois em um processo ético-disciplinar ou judicial, são estes aspectos que serão avaliados, se foram cumpridos ou não durante a assistência médica.

$\mathrm{Na}$ literatura foram encontrados reflexões e trabalhos de revisão bibliográfica que abordaram sobre ética e responsabilidade médica, todavia, poucas pesquisas de campo foram realizadas afim de se observar se os médicos conhecem tais temas. Desse modo, este trabalho 
teve por objetivo avaliar a percepção dos médicos do Hospital Regional de Presidente Prudente (HRPP) - SP acerca dos aspectos éticos e legais envolvidos na prática médica, bem como correlacionar esse dado com as variáveis sexo, idade, graduação em instituição pública ou privada e tempo de exercício da profissão.

\section{MÉTODOS}

Trata-se de um estudo transversal descritivo, aprovado pelo Comitê de Ética em Pesquisa da Universidade do Oeste Paulista (CAAE no 55113616.0.0000.5515). A amostra foi constituída de médicos do HRPP - SP, sendo que os mesmos foram abordados dentro do referido hospital, em seu ambiente de trabalho, como consultórios, enfermarias e pronto-socorro, sendo incorporados ao estudo de maneira aleatória. Foram esclarecidos sobre a pesquisa e após aceitação, por meio do Termo de Consentimento Livre e Esclarecido (TCLE), responderam ao questionário autoaplicável (em anexo).

O questionário foi dividido em duas partes. A primeira contendo questões sobre as características dos médicos em estudo, como idade, sexo, graduação em Instituição de Ensino Superior (IES) pública ou privada e tempo de exercício da medicina. A variável idade foi classificada em três faixas etárias: $\leq 30$ anos, 31-59 anos e $\geq 60$ anos. A variável tempo de exercício da medicina também foi dividida em três grupos: $\leq 2$ anos, 2,1-10 anos e $\geq 11$ anos. A segunda parte do questionário, contendo questões objetivas, abordou diversas áreas de conhecimento: responsabilidade médica (questões 1 e 2), erro médico (questão 4), deveres de conduta do médico (questões $3,7,8,9,10,14$ ), princípios da bioética (questões $5,11,12$ e 13) e medicina defensiva (questões 6 e 15).

Por não encontrarmos nenhum questionário validado com médicos e que abordasse todos os temas que desejamos estudar, o questionário desta pesquisa foi elaborado pelos próprios autores, sendo que as questões envolveram a aplicação de conceitos em exemplos práticos encontrados no dia-a-dia do médico, sem se questionar diretamente a definição do assunto, o que induziria o médico a responder as questões, mesmo que não tivesse conhecimento. As respostas constituíram uma escala de Likert, com as seguintes opções gradativas: "discorda totalmente", "discorda parcialmente", "nem discorda nem concorda", "concorda parcialmente" e "concorda totalmente". Apenas uma alternativa foi considerada como correta, sendo definida com base no CEM publicado pelo Conselho Federal de Medicina em 2009, no novo Código Civil e no Código de Defesa do Consumidor. As questões cujas respostas ficaram em branco ou assinaladas mais de uma alternativa foram invalidadas e, portanto, excluídas da análise estatística.

As respostas obtidas foram tabuladas e arquivadas em banco de dados construído em planilha eletrônica (Microsoft Excel ${ }^{\oplus}$ ). Os dados foram descritos por meio de distribuições de frequências relativas (\%) e absolutas (n). Os testes qui-quadrado, $G$ ou exato de Fisher foram utilizados para correlacionar o perfil do médico (sexo, idade, tempo de exercício da medicina e formação em IES pública ou privada) com o nível de percepção acerca dos aspectos éticos e legais da prática médica. As análises estatísticas foram realizadas no programa Bioestat 5.3 utilizando nível de significância de $5 \%(p<0,05)$.

\section{RESULTADOS}

A população desta pesquisa foi composta por 150 médicos vinculados ao HRPP-SP, sendo $53,4 \%$ do sexo feminino e $46,6 \%$ do sexo masculino. A maioria dos indivíduos pesquisados teve idade $\leq 30$ anos $(74,7 \%)$ e graduou-se em IES privada (84,5\%). No que diz respeito ao tempo de exercício da medicina, 46,6\% dos médicos tinham $\leq 2$ anos de atuação, 41,1\% 2,1-10 anos de atuação e apenas $12,3 \% \geq 11$ anos de exercício da profissão (Tabela 1). 
Tabela 1. Caracterização do perfil dos médicos do HRPP-SP, 2016.

\begin{tabular}{lcc}
\hline Sexo (n=148) & $\mathbf{n}$ & \% \\
\hline Feminino & 79 & 53,4 \\
Masculino & 69 & 46,6 \\
\hline Faixa etária (n=150) & & 74,7 \\
\hline 30 anos & 112 & 21,3 \\
$31-59$ anos & 32 & 4,0 \\
$\geq 60$ anos & 6 & 84,5 \\
\hline IES (n=142) & & 15,5 \\
\hline Privada & 120 & \\
Pública & 22 & 46,6 \\
Tempo de exercício da medicina (n=146) & & 41,1 \\
\hline 2 anos & 68 & 12,3 \\
$2,1-10$ anos & 60 & \\
$\geq 11$ anos & 18 &
\end{tabular}

Os resultados da segunda parte do questionário, que abordou 15 questões objetivas, acerca dos temas responsabilidade médica (questões 1 e 2), erro médico (questão 4), deveres de conduta do médico (questões 3,7,8,9,10,14), princípios da bioética (questões 5, 11, 12 e 13) e medicina defensiva (questões 6 e 15); podem ser observados na tabela 2. A questão 15 pedia para o participante expressar sua opinião quanto à pratica da medicina defensiva, logo não possui resposta correta ou incorreta.

Tabela 2. Respostas dos médicos do HRPP-SP à segunda parte do questionário, 2016.

\begin{tabular}{ccccccc}
\hline Questão & $\mathbf{n}$ & $\begin{array}{c}\text { Discorda } \\
\text { totalmente }\end{array}$ & $\begin{array}{c}\text { Discorda } \\
\text { parcialmente }\end{array}$ & $\begin{array}{c}\text { Nem } \\
\text { concorda } \\
\text { nem } \\
\text { discorda }\end{array}$ & $\begin{array}{c}\text { Concorda } \\
\text { parcialmente }\end{array}$ & $\begin{array}{c}\text { Concorda } \\
\text { totalmente }\end{array}$ \\
\hline 1 & 150 & $14,0^{*}$ & 31,3 & 13,3 & 28,7 & 12,7 \\
2 & 150 & $2,0^{*}$ & 12,7 & 2,7 & 38,7 & 44,0 \\
3 & 149 & 4,7 & 13,4 & 2,7 & 35,6 & $43,6^{*}$ \\
4 & 150 & $60,7^{*}$ & 20,7 & 2,7 & 9,2 & 6,7 \\
5 & 150 & 30,0 & 20,0 & 19,3 & 23,3 & $7,3^{*}$ \\
6 & 150 & $30,0^{*}$ & 24,0 & 14,0 & 22,0 & 10,0 \\
7 & 150 & 0,70 & 2,7 & 1,3 & 11,3 & $84,0^{*}$ \\
8 & 149 & $78,5^{*}$ & 12,1 & 4,0 & 4,7 & 0,7 \\
9 & 150 & $35,3^{*}$ & 24,0 & 12,7 & 25,3 & 2,7 \\
10 & 147 & 0,70 & 13,6 & 5,4 & 25,9 & $54,4^{*}$ \\
11 & 143 & 8,4 & 20,3 & 7,0 & 26,5 & $37,8^{*}$ \\
12 & 146 & $61,0^{*}$ & 25,3 & 4,8 & 6,8 & 2,1 \\
14 & 146 & $22,6^{*}$ & 29,5 & 16,4 & 15,1 & 16,4 \\
\hline
\end{tabular}

* Resposta esperada para a questão

** Questão que avalia a opinião pessoal (não possui resposta esperada)

Na questão 15 foi colocado ao participante o próprio conceito da medicina defensiva e foi pedido a sua opinião acerca dessa prática. Observamos que foi a questão com maior número de médicos indecisos, que não conseguiram se posicionar, com 30,8\% das respostas "nem discorda nem concorda". A segunda resposta mais prevalente foi "discorda totalmente", com $21,7 \%$. Porém, ao considerarmos nesta questão o número de participantes que concordaram com a medicina defensiva, seja totalmente ou parcialmente, o percentual foi superior aos que discordaram totalmente somado ao parcialmente, totalizando 37,8\% favoráveis contra 31,5\% desfavoráveis à medicina defensiva. Pensando na aplicação do conceito da medicina defensiva na prática médica diária, foi elaborada a questão 6 , e verificamos que a resposta mais prevalente foi a 
considerada como correta (discorda totalmente), com 30,0\%, e não a resposta que sugere indecisão (nem discorda nem concorda) como visto na questão 17 que abordou apenas o conceito.

A questão 4 discutiu sobre "erro médico", trazendo em seu enunciado uma das definições encontradas na literatura brasileira: "erro médico é o dano provocado ao paciente, decorrente da conduta do médico, com a intenção de cometê-lo". 60,7\% dos médicos "discordaram totalmente" dessa afirmativa, demonstrando compreender que o erro médico não pode ser caracterizado quando há dolo.

Com relação ao tema "responsabilidade médica", verificou-se nível de percepção baixo, uma vez que somente $14,0 \%$ e $2,0 \%$ dos médicos acertaram as questões de número 1 e 2 , respectivamente.

O assunto em que os médicos demonstraram maior percepção foi "deveres de conduta do médico", mais especificamente sobre o dever de informar, na qual foram feitas três questões: 7, 8 e 14. As questões 7 e 8 foram elaboradas de maneira mais simplificada, trazendo quase que apenas o conceito retirado do CEM, assim observamos que o nível de percepção foi bem superior (84,0\% e 78,5\% de acertos, respectivamente) quando comparado com a questão 14 (19,9\% de acertos), que também discutia sobre o dever de informar, porém aplicando este conceito em um caso prático, que exigiu conhecimento do Termo de Consentimento Informado. A questão 3 somou 43,6\% de acertos e abordou o dever de "vigilância" do médico. Com relação ao dever de "abstenção de abuso" (questão 9), somente 35,3\% dos médicos responderam adequadamente e quanto ao dever de "atualização" (questão 10), 54,4\% dos profissionais estavam cientes.

No que se refere aos "princípios da bioética", com relação à "não-maleficência" foram feitas duas questões. Na questão 12, em que a abordagem do tema foi mais direta e simplificada, mais da metade dos médicos acertaram a questão (61,0\%). No entanto, a questão 5 trouxe o assunto de uma maneira mais conflituosa, responsabilizando o médico por uma complicação resultante de um procedimento realizado corretamente, porém, mal indicado, assim, apenas 7,3\% acertaram quando "concordaram totalmente". A questão 11 exemplificou o princípio bioético da "autonomia" e notou-se $37,8 \%$ de respostas esperadas. Com relação ao princípio da "justiça" (questão 13) foi verificado uma lacuna de conhecimento, uma vez que somente $22,6 \%$ dos médicos "discordaram totalmente" com a assertiva: "não é justificável o médico decidir dedicar mais atenção a qualquer paciente, devendo oferecer tratamento estritamente isonômico a todos".

No quadro 3 são apresentadas as correlações entre o percentual das respostas respondidas corretamente e as variáveis analisadas. Não foi encontrada nenhuma correlação entre sexo e maior prevalência de acertos nas questões. Com relação à idade dos médicos participantes observou-se na questão 5 , que se falava do princípio bioético da não-maleficência, que as faixas etárias de 31-59 anos e $\geq 60$ anos obtiveram maior percentual de acertos em relação a faixa etária mais jovem de até 30 anos de idade $(p=0,0198)$. Já na questão 13 , que abordou um outro princípio bioético, o da justiça, verificou-se associação entre o grupo de até 30 anos de idade e também os maiores de 60 anos, com maior proporção de respostas adequadas $(p=0,0322)$. 


\begin{tabular}{|c|c|c|c|c|c|c|c|c|c|c|}
\hline & \multicolumn{2}{|c|}{ Sexo } & \multicolumn{3}{|c|}{ Idade (anos) } & \multicolumn{2}{|c|}{ IES } & \multicolumn{3}{|c|}{$\begin{array}{l}\text { Tempo exercício da medicina } \\
\text { (anos) }\end{array}$} \\
\hline & $\mathbf{F}$ & $M$ & $\leq \mathbf{3 0}$ & 31-59 & $\geq 60$ & Pública & Privada & $\geq 2$ & $2,1-10$ & $\geq 11$ \\
\hline 1 & 10,1 & 18,8 & 12,5 & 21,9 & 0,0 & 11,7 & 22,7 & 10,3 & 15,0 & 22,2 \\
\hline$p$ & \multicolumn{2}{|c|}{0,1296} & \multicolumn{3}{|c|}{0,1762} & \multicolumn{2}{|c|}{0,1613} & \multicolumn{3}{|c|}{0,4142} \\
\hline 2 & 2,6 & 1,5 & 0,9 & 6,3 & 0,0 & 0,0 & 10,0 & 1,5 & 0,0 & 5,6 \\
\hline$p$ & \multicolumn{2}{|c|}{0,5509} & \multicolumn{3}{|c|}{0,2208} & \multicolumn{2}{|c|}{0,0231} & \multicolumn{3}{|c|}{0,2247} \\
\hline 3 & 46,8 & 39,7 & 46,0 & 37,5 & 33,3 & 46,7 & 36,4 & 49,3 & 36,7 & 50,0 \\
\hline$p$ & \multicolumn{2}{|c|}{0,3847} & \multicolumn{3}{|c|}{0,6059} & \multicolumn{2}{|c|}{0,3719} & \multicolumn{3}{|c|}{0,3110} \\
\hline 4 & 62,0 & 60,9 & 64,3 & 50,0 & 50,0 & 61,7 & 54,6 & 66,2 & 60,0 & 38,9 \\
\hline$p$ & \multicolumn{2}{|c|}{0,8854} & \multicolumn{3}{|c|}{0,3024} & \multicolumn{2}{|c|}{0,5298} & \multicolumn{3}{|c|}{0,1135} \\
\hline 5 & 7,6 & 7,2 & $3,6 b$ & $18,8 a$ & $16,7 a$ & 6,7 & 13,6 & $2,9 b$ & $6,7 b$ & $27,8 a$ \\
\hline$p$ & \multicolumn{2}{|c|}{0,9357} & \multicolumn{3}{|c|}{0,0198} & \multicolumn{2}{|c|}{0,2308} & \multicolumn{3}{|c|}{0,0094} \\
\hline 6 & 29,1 & 31,9 & 26,8 & 37,5 & 50,0 & 24,2 & 50,0 & $16,2 b$ & $41,7 a$ & $44,4 a$ \\
\hline$p$ & \multicolumn{2}{|c|}{0,7148} & \multicolumn{3}{|c|}{0,2965} & \multicolumn{2}{|c|}{0,0133} & \multicolumn{3}{|c|}{0,0021} \\
\hline 7 & 81,0 & 88,4 & 82,1 & 90,6 & 83,3 & 82,5 & 86,4 & 79,4 & 85,0 & 94,4 \\
\hline$p$ & \multicolumn{2}{|c|}{0,2155} & & 0,4779 & & & & & 0,236 & \\
\hline 8 & 75,6 & 82,6 & 77,5 & 81,3 & 83,3 & 75,6 & 95,5 & 70,2 & 85,0 & 83,3 \\
\hline$p$ & & & & 0,8588 & & & & & 0,109 & \\
\hline 9 & 35,4 & 36,2 & 36,6 & 37,5 & 0,0 & 36,7 & 31,8 & 33,8 & 39,0 & 33,3 \\
\hline$p$ & & & & 0,0680 & & & & & 0,848 & \\
\hline 10 & 59,7 & 48,5 & 55,5 & 54,8 & 33,3 & 55,6 & 54,6 & 56,7 & 50,0 & 55,6 \\
\hline$p$ & & & & 0,5681 & & & & & 0,745 & \\
\hline 11 & 39,5 & 39,9 & 37,7 & 38,7 & 33,3 & 39,5 & 36,4 & 37,5 & 35,1 & 50,0 \\
\hline$p$ & & & & 0,9691 & & & & & 0,527 & \\
\hline 12 & 59,2 & 64,7 & 62,4 & 64,5 & 16,7 & 59,5 & 63,6 & 57,6 & 65,5 & 55,6 \\
\hline$p$ & & & & 0,0725 & & & & & 0,595 & \\
\hline 13 & 33,3 & 16,2 & $25,7 \mathrm{a}$ & $6,4 b$ & $33,3 a$ & 19,8 & 31,8 & 19,4 & 24,6 & 22,2 \\
\hline$p$ & & & & 0,0322 & & & & & 0,786 & \\
\hline 14 & 19,7 & 20,6 & 17,4 & 25,8 & 33,3 & 20,7 & 18,2 & 22,7 & 10,3 & 33,3 \\
\hline$p$ & & & & 0,4360 & & & & & 0,168 & \\
\hline
\end{tabular}

Quadro 3. Correlações das frequências percentuais (\%) das questões respondidas corretamente e as variáveis selecionadas no estudo, 2016.

A prevalência de conhecimentos satisfatórios sobre os temas responsabilidade médica (questão 2), medicina defensiva (questão 6) e o dever de conduta informar (questão 8) apresentou associação com a formação médica em IES pública ( $p=0,0231 ; 0,0133 ; 0,0261$, respectivamente).

Foi encontrada correlação positiva entre a percepção da prática da medicina defensiva (questão 6) e maior tempo de atuação profissional ( $p=0,0021)$, sendo que os médicos com mais de 2 anos de exercício da medicina (grupos 2,1-10 anos e $\geq 11$ anos) obtiveram maior percentual de acertos em relação aos médicos com menos de 2 anos. Considerando ainda esta variável, verificou-se maior conhecimento do princípio bioético da não-maleficência (questão 5) entre os médicos com $\geq 11$ anos de prática médica $(p=0,0094)$.

\section{DISCUSSÃO}

É indiscutível a progressiva demanda de ações nos Conselhos de Medicina buscando condenação por infração ética, e no Judiciário, em busca de reparação frente a denúncias de responsabilidade civil e/ou penal do profissional de saúde, consequentes a erro médico ${ }^{7}$. Diante deste cenário, cada vez mais os médicos se utilizam de práticas "de defesa" para evitar tais ações, como abusar dos pedidos de exames, prescrever medicamentos não justificados e encaminhar pacientes para outros médicos sem necessidade. Um estudo realizado no México mostrou que $61 \%$ dos médicos utilizam práticas defensivas ${ }^{8}$. No Brasil, embora sem estudos específicos sobre 0 assunto, Minossi e Silva (2013) afirmam que há consolidação da medicina defensiva na prática médica diária ${ }^{3}$. Em nosso estudo, por meio de duas questões abordamos o assunto e verificamos Colloquium Vitae, vol. 9, n. Especial, Jul-Dez, 2017, p.39 -50. ISSN: 1984-6436. DOI: 10.5747/cv.2017.v09.nesp.000297 
que quando exposto apenas o conceito da medicina defensiva ("a medicina defensiva é uma prática médica que prioriza condutas diagnósticas e/ou terapêuticas, encaminhamentos frequentes de pacientes a outros especialistas e até mesmo a recusa ao atendimento de pacientes graves e com maior potencial de complicações, tudo com o objetivo de se evitar demandas nos tribunais", questão 15$), 37,8 \%$ dos médicos concordaram com tal prática (17,5\% concordaram totalmente e $20,3 \%$ parcialmente), 31,5\% discordaram (21,7\% totalmente e $9,8 \%$ parcialmente) e $30,8 \%$ ficaram indecisos. Porém, quando foi aplicado o conceito da medicina defensiva em um exemplo prático (questão 6), verificou-se que o percentual de médicos indecisos diminuiu para $14 \%$ e mais da metade dos médicos (54\%) passaram a discordar desta prática médica (30\% discordaram totalmente e $24 \%$ parcialmente). Observou-se correlação entre o percentual de acertos da questão 6 e as variáveis graduação em IES pública e tempo de exercício da medicina de 2,1-10 anos e $\geq 11$ anos ( $p=0,0021)$, ou seja, os médicos formados em universidades públicas e com maior tempo de exercício da profissão foram mais discordantes em relação à medicina defensiva, ou seja, discordaram da solicitação de muitos exames complementares, que não se enquadram no protocolo padrão de investigação de uma doença, em relação aos médicos graduados em instituições privadas e aqueles com $\leq 2$ anos de atuação. Isso pode ser devido à precária formação médica em nosso país, com abertura indiscriminada de escolas médicas, que não proporcionam qualidade no ensino, fazendo com que o profissional recém ingressado no mercado de trabalho, ainda inseguro e com medo de ser acusado por negligência, utilize mais de meios requintados de diagnósticos em detrimento à anamnese e exame clínico pormenorizado.

O erro médico é o dano provocado no paciente pela ação ou inação do médico, no exercício da profissão, e sem a intenção de cometê-lo ${ }^{9}$. Ele pode ser arguido sob duas formas de responsabilidade, a legal e a moral. A responsabilidade moral é da competência dos Conselhos de Medicina, através de processos ético-disciplinares, embasados no CEM. Já a responsabilidade legal é atribuída pelos tribunais, podendo comportar, entre outras, as ações penais e civis. A responsabilidade penal do médico é regulada principalmente pelo Código Penal e a responsabilidade civil é disciplinada pelo Código de Defesa do Consumidor e pelo novo Código Civil. Não é comum nos processos por erro médico, que o mesmo seja processado criminalmente, e sim civilmente, pois o que se deseja é, de um modo geral, a reparação financeira do dano. Porém, muitos médicos desconhecem que sua responsabilidade é do tipo subjetiva, logo, para efetivar o erro médico e gerar o dever de reparação são necessários alguns requisitos: 1) 0 autor: é necessário que o profissional esteja habilitado legalmente para o exercício da medicina, caso contrário, além de responsabilizado, será punido por exercício ilegal da medicina, curandeirismo ou charlatanismo. 2) $\mathrm{O}$ ato: que deverá ser o resultado danoso de um ato lícito, pois, do contrário, trata-se de uma inflação delituosa mais grave, como por exemplo, o aborto criminoso ou a eutanásia. 3) A culpa: por maior que seja o dano, o médico só será condenado se houver culpa, que consiste na ausência do dolo, ou seja, que o autor tenha produzido o dano sem a intenção de prejudicar, mas o tenha feito por negligência, imprudência ou imperícia. 4) 0 dano: sem a existência de um dano real, efetivo e concreto não existe responsabilidade. 5) O nexo causal: é a relação entre causa e efeito, um elo entre o ato e o dano ${ }^{10}$. Com relação ao erro médico (questão 4), verificamos que $60,7 \%$ dos médicos sabiam a sua definição, no entanto, 39,3\% desconheciam, uma vez que não discordaram totalmente ao ler o conceito de que o "erro médico é o dano provocado ao paciente, decorrente da conduta do médico, com a intenção de cometê-lo". Em sua obra "Erro médico e responsabilidade civil", Correia-Lima (2012) diz que o erro médico é a conduta (omissiva ou comissiva) profissional atípica, irregular ou inadequada, contra o paciente durante ou em face de exercício médico que pode ser caracterizado como imperícia, negligência ou imprudência, mas nunca como dolo ${ }^{7}$.

Cada vez mais os médicos se preocupam com a possibilidade de terem que enfrentar os tribunais, mas, na maioria das vezes, conhecem pouco sobre o assunto ${ }^{1}$, e isso foi constatado em 
nossa pesquisa quando abordamos a responsabilidade médica na questão 2 , que dizia: "o médico que age perante seu paciente com descaso, ou toma uma atitude precipitada, ou ainda realiza um procedimento sem ter o preparo técnico suficiente, deve ser responsabilizado, mesmo que não tenha causado dano ao paciente". Com apenas $2 \%$ dos médicos discordando totalmente desta assertiva, verificamos a deficiência no conhecimento acerca dos elementos necessários para que se possa configurar o erro médico e a responsabilidade médica. Neste exemplo, mesmo o médico sendo considerado culpado por ter sido imperito, imprudente e negligente, o mesmo não será responsabilizado, pois não causou nenhum dano ao seu paciente. Não há, juridicamente, erro médico sem dano ou agravo à saúde de terceiro. A falta do dano, que é da essência e um dos pressupostos básicos do erro médico, descaracteriza o erro, inviabiliza o seu ressarcimento e desconfigura a responsabilidade civil ${ }^{7}$.

O CEM estabelece que é vedado ao médico "causar dano ao paciente, por ação ou omissão, caracterizável como imperícia, imprudência ou negligência" ${ }^{6}$, sendo portanto, as três formas bem estabelecidas de culpa do médico em sua atuação profissional, o que também o torna culpado na justiça civil. Considera-se como negligência o descaso, inação e passividade, sendo a falta de observância aos deveres que as circunstâncias exigem, um ato omissivo. Já a imprudência tem sempre caráter comissivo, isto é, resulta de uma atuação e não de omissão e pode ser definida como ação precipitada, irrefletida, em que o profissional não se preocupou em evitar o dano previsível, não agindo com a cautela necessária. Imperícia é a falta de observação às normas, por despreparo prático ou por insuficiência de conhecimentos técnicos. Como na medicina existe grande margem para a ocorrência de situações imprevisíveis, é importante distinguir o erro médico de acidente imprevisível e de resultado incontrolável. No acidente imprevisível, há um resultado lesivo, supostamente oriundo de caso fortuito ou força maior à integridade física ou psíquica do paciente durante $\mathrm{o}$ ato médico. $\mathrm{O}$ resultado incontrolável seria aquele decorrente de uma situação grave e de curso inexorável, isto é, aquele resultado danoso proveniente de sua própria evolução, para o qual as condições atuais da ciência e a capacidade profissional ainda não oferecem solução. Nestes dois casos, o médico tendo agido com zelo e cuidado, jamais poderá ser responsabilizado. Por isso, os médicos em geral, tem com o paciente a "obrigação de meios" e não de "resultados", assumindo compromisso de agir com diligência e de usar seus conhecimentos na busca de um resultado favorável, o qual nem sempre é certo, cabendo ao paciente demonstrar culpa ou dolo a justificar a reparação pretendida ${ }^{1}$. Desse modo, constatou-se novamente a insatisfatória percepção dos médicos deste estudo com relação ao tema responsabilidade médica, uma vez que $86,0 \%$ deles acreditam, erroneamente, que o médico que realiza um procedimento em qualquer especialidade da medicina e obtém resultado indesejado deve ser responsabilizado (questão 1). Isto pode demonstrar desconhecimento sobre o tipo de responsabilidade do médico, que talvez se deva, em parte, ao pouco contato que os estudantes têm com este assunto durante a graduação e nos leva a crer na necessidade de medidas mais eficazes para promover o processo de ensino-aprendizagem durante a graduação, buscando identificar e corrigir falhas, para que o conhecimento adquirido pelos estudantes não seja incorreto, insuficiente ou efêmero.

Minossi (2009) relata que qualquer que seja a forma de avaliar a responsabilidade de um profissional em determinado ato médico, no âmbito ético ou legal, é imprescindível que se levem em conta seus deveres de conduta ${ }^{1}$. Infelizmente, há vários anos se tem notado um aumento no número de processos e punições a médicos que cometeram infrações que ferem o $\mathrm{CEM}^{11}$. Deste modo também avaliamos a percepção dos médicos quanto aos seus deveres de informar, atualizar, vigilância e abstenção de abuso e observamos que apesar dos maiores percentuais de acertos do questionário se concentrarem nas questões 7 e 8 , sobre o dever do médico de informar, quando foi abordado sobre o Termo de Consentimento Informado (questão 14), somente $19,9 \%$ deles conseguiram associar que o médico que não produz tal termo anteriormente à realização de um procedimento mal sucedido em seu paciente, poderá ser 
responsabilizado pelo não cumprimento de um dos seus deveres de conduta, o de dar informação, mesmo que tenha realizado o procedimento seguindo perfeitamente a melhor técnica existente. O consentimento informado é uma ferramenta útil não apenas para o paciente, que toma ciência de sua própria saúde, mas também para o médico, uma vez que em medicina podem ocorrer situações inesperadas, em que cada paciente pode reagir de uma maneira diante de um procedimento ou terapia, cabendo ao paciente decidir pelo sim ou pelo não, isso a partir das informações dos riscos e benefícios fornecidas pelo médico. Nos casos de consentimento positivo seguido de um resultado indesejado, o paciente não pode responsabilizar o médico, desde que o mesmo tenha procedido sem culpa. O paciente devidamente informado é coparticipante da decisão, levando-o a realizar um juízo de reflexão, que certamente trará maiores ponderações antes de buscar a tutela do judiciário. Ocorre que, diante da inexistência do consentimento informado, mesmo que o médico empregue todos os meios disponíveis, se houver dano, ele será responsabilizado pelo não cumprimento de um dos seus deveres, que por outro lado constitui direito do paciente, que é o de receber todas as informações para ter a capacidade de decidir sobre as ações que possam incidir sobre a sua integridade física. Quando não há o consentimento informado, o paciente pode alegar que se soubesse dos riscos sua decisão seria pela não submissão ao tratamento que ocasionou modificação no seu organismo ou mesmo lesão permanente, inclusive no caso em que o dano tenha ocorrido por fato inesperado (caso fortuito ou força maior), como por exemplo, uma reação inesperada e adversa à medicação ${ }^{12}$.

Acredita-se que os médicos desde o momento que decidiram por esta profissão sabiam da necessidade que teriam, mesmo depois de formados, de se atualizarem, uma vez que a medicina evolui, e com ela os conceitos, as técnicas, os aparelhos e ao mesmo tempo, as doenças. No entanto, o que observamos é que talvez muitos médicos desconhecem que a atualização se constitui em um dever de conduta previsto no CEM, e que sua capacitação profissional é sempre verificada toda vez que se discute responsabilidade médica, uma vez que $45,6 \%$ dos pesquisados não concordaram totalmente quando se falava na questão 10 que o médico poderá ser considerado imperito quando não mantem-se atualizado em seus conhecimentos. Portanto, o regular exercício profissional do médico não requer apenas uma habilitação legal, mas também requer o aprimoramento continuado, adquirido por meio dos conhecimentos mais recentes da profissão.

$\mathrm{Na}$ avaliação de um dano produzido por um ato médico, deve ficar claro se o profissional agiu com a cautela devida, uma vez que exceder-se na terapêutica ou nos meios propedêuticos mais arriscados é uma forma de desvio de poder e, se o dano deveu-se a isso, não há como negar a responsabilidade. Sendo assim, usar abusivamente de meios diagnósticos invasivos ou não, indicar operações desnecessárias, realizar experiências no ser humano fora de protocolos de estudo e sem o devido consentimento, são algumas formas de abuso, que por vezes terminam em dano ao paciente e, portanto, são passíveis de condenação do médico ${ }^{1}$. Assim, considera-se essencial o conhecimento médico do seu dever de "abstenção de abuso", e infelizmente, verificamos que somente $35,3 \%$ deles tiveram adequada percepção (questão 9).

As deficiências observadas na percepção dos médicos estudados quanto aos seus deveres de conduta nos leva a refletir sobre o modelo clássico de ensino da ética através da disciplina de Medicina Legal e Deontologia, que possa ter se tornado insuficiente para atender às necessidades cotidianas do médico. Talvez seja necessário ensinar ética médica durante toda a graduação, o que não é realidade nas instituições de ensino no Brasil. Godoy, Ferreira e Pria (2014) acreditam que para que o conhecimento sobre ética fique inerente ao pensamento, o ideal seria selecionar os principais temas sobre o assunto, compilando-se os que se adaptem melhor a cada estágio e fixando curricularmente no plano de ensino de cada disciplina discussões sobre esses temas na rotina de cada enfermaria, de modo a estimular o graduando a analisar suas atitudes com os pacientes, pautando-se no $\mathrm{CEM}^{13}$. Assim, seriam introduzidas na realidade do acadêmico as 
condutas frente a casos que exijam ações éticas, que com certeza surgirão no cotidiano de sua profissão.

Em 1979, os norte-americanos Tom Beauchamp e James Childress publicaram um livro chamado "Principles of Biomedical Ethics", onde expõem uma teoria fundamentada em quatro princípios básicos (não-maleficência, beneficência, justiça e autonomia) que são utilizados como regras gerais para orientar a tomada de decisão frente aos problemas éticos que emergem da prática da assistência à saúde e para ordenar os argumentos nas discussões de $\operatorname{casos}^{14}$. Em nossa pesquisa foi abordado três destes princípios e de modo geral pudemos verificar que a percepção não foi satisfatória, uma vez que a porcentagem de acertos com relação aos princípios da "autonomia" (questão 11), "justiça" (questão 13) e "não-maleficência" (questão 5) foi de apenas $37,8 \%, 22,6 \%$ e $7,3 \%$, respectivamente. Resultado semelhante foi encontrado em uma pesquisa realizada com 250 médicos nigerianos no ano de 2012, em que houve diferença significativa entre o nível de conhecimento para cada princípio bioético, sendo que 55,6\% dos entrevistados sabiam sobre o princípio da autonomia, 48,7\% estavam cientes do princípio da beneficência, 40,2\% conheciam sobre a não-maleficência, enquanto apenas 31,7\% tinham algum conhecimento sobre o princípio da justiça ${ }^{15}$. Este baixo nível de conhecimento é preocupante, pois subentende-se que a maioria dos médicos terão dificuldades em identificar casos óbvios com dilemas éticos e isso afetará a forma como estes casos serão geridos. O desconhecimento do princípio da autonomia e da sua aplicação na prática poderá criar problemas com o paciente e também com sua a família, quando os mesmos não são incluídos nas decisões médicas, questionamento levantado na questão 11 , em que somente $37,8 \%$ dos médicos acertaram. Ignorância sobre o princípio da justiça poderá acarretar em falhas no gerenciamento das verbas destinadas à saúde e no funcionamento do sistema, uma vez que indica que os recursos disponíveis não serão utilizados com prudência e equidade, tendo ainda maior importância nos locais em que estes recursos são escassos, como em grande parte dos estados brasileiros. Assim como em nossa pesquisa, o estudo com os 250 médicos nigerianos também não encontrou diferença significativa nas respostas corretas com relação ao sexo feminino e masculino.

Em relação ao princípio da não-maleficência (questão 5), foi verificada associação entre sua adequada percepção e as faixas etárias 31-59 anos e $\geq 60$ anos $(p=0,0198)$, bem como tempo de exercício da medicina $\geq 11$ anos $(p=0,0094)$. Resultados estes que corroboram com os encontrados em um estudo realizado no Paquistão, no ano de 2005, que teve por objetivo avaliar o conhecimento e a prática da ética médica entre médicos residentes da cirúrgica. Os pesquisadores observaram que os médicos que graduaram-se nos últimos 10 anos (após o ano de 1995) obtiveram menor número de acertos em relação aos que graduaram-se há mais de 10 anos (antes de 1995$)^{16}$. Brogen, Rajkumari e Laishram (2009) ao realizarem uma pesquisa afim de avaliar o conhecimento e as atitudes em relação à ética médica entre os médicos do Instituto Regional de Ciências Médicas de Imphal, Manipur, também verificaram que o conhecimento da ética médica foi maior entre aqueles que tinham mais de 35 anos de idade e aqueles que se graduaram antes de 1999 , ou seja, aqueles com mais de 10 anos de tempo de exercício da medicina ${ }^{17}$. Este fato talvez possa ser explicado pela maior experiência médica que os anos trabalhados conferem ao profissional. Os médicos mais velhos, que por conseguinte possuem mais anos de atuação profissional, já puderam vivenciar muito mais problemas éticos em seu dia-a-dia em relação aos médicos mais jovens com poucos anos de atuação, e com isso puderam aprender, seja com seus erros ou acertos, a conduta correta.

Um fator limitante nesta pesquisa foi a extensão do questionário, que por conter 17 questões, muitos médicos alegaram no momento de sua abordagem estarem atrasados para compromissos profissionais ou pessoais e não terem tempo suficiente para respondê-lo.

Este estudo se diferencia dos demais por ser o primeiro a avaliar especificamente a percepção dos médicos sobre ética e responsabilidade médica aplicadas em exemplos da prática 
clínica. Não encontramos nenhum outro trabalho na literatura nacional ou internacional com esta característica.

\section{CONCLUSÕES}

De maneira geral, os resultados evidenciaram deficiências importantes na percepção dos médicos estudados sobre os temas ética e responsabilidade médica. A princípio este é um dado preocupante, contudo, considerando que o questionário aplicado trata-se de um instrumento artificial, talvez não reflita as atitudes dos médicos ao se depararem com situações reais. Por isso se fazem necessárias mais pesquisas de campo para melhor fundamentação acerca do conhecimento médico.

\section{AGRADECIMENTOS}

Agradecemos ao Centro de Bioética do Conselho Regional de Medicina do Estado de São Paulo (CREMESP) pelo financiamento desta pesquisa, por meio do Programa de Bolsas em Ética Médica e Bioética 2016.

\section{CONFLITOS DE INTERESSE}

Os autores declaram não haver qualquer potencial de conflito de interesse que possa interferir na imparcialidade deste trabalho científico.

\section{REFERÊNCIAS}

1. Minossi JG. Prevenção de conflitos médico-legais no exercício da medicina. Rev Col Bras Cir. 2009. 36(1):90-5. DOI: http://dx.doi.org/10.1590/S0100-69912009000100016.

2. Matiello FZ. Responsabilidade civil do médico. 4. ed. São Paulo: LTr, 2014.

3. Minossi JG, Silva AL. Medicina defensiva: uma prática necessária? Rev Col Bras Cir. 2013. 40(6):494-501. DOI: http://dx.doi.org/10.1590/S0100-69912013000600013

4. Ribas-Filho JM. O porque dos altos custos na área médica e da saúde. Arq Bras Cir Dig. [Internet]. 2011. 24(3):189-190. DOI: http://dx.doi.org/10.1590/S0102-67202011000300001

5. Woolhandler S, Campbell T, Himmelstein DU. Costs of Health Care Administration in the United States and Canada. N Engl J Med. 2003. 349:768-775. DOI: 10.1056/NEJMsa022033, https://doi.org/10.1056/NEJMsa022033.

6. Conselho Federal de Medicina. Código de Ética Médica: resolução CFM n 1931/2009. Brasília: CFM. 2009 Disponível:https://portal.cfm.org.br/index.php?option=com_content\&view=category\&id=9\&ltemi $d=122$

7. Correia-Lima FG. Erro médico e responsabilidade civil. [Internet]. Brasília: Conselho Federal de Medicina, Conselho Regional de Medicina do Estado do Piauí, 2012. ISBN 978-85-87077-25-7. Disponível:

https://portal.cfm.org.br/images/stories/biblioteca/erromedicoresponsabilidadecivil.pdf

8. Sánches GJM, Tena TC, Campos CEM, Hernández GLE, Rivera CAE. Medicina defensiva en México: una encuesta exploratoria para su caracterización. Cir Cir. 2005. 73(3):199-206. Disponível: http://www.medigraphic.com/pdfs/circir/cc-2005/cc053h.pdf 
9. Gomes JCM, Drumond JGF, França GV. Erro Médico. 3. ed. Rev.atual. Montes Claros: Ed. Unimontes, 2001.

10. Veloso FG. Direito médico. 8. ed. São Paulo: BYK; 2003.

11. Conselho Regional de Medicina do Estado de São Paulo (CREMESP). Exame do Cremesp agora é obrigatório. 2012. Disponível: http://www. cremesp.org.br/pdfs/exame_cremesp_24_ultimo.pdf

12. Silva CA. O consentimento informado e a responsabilidade civil do médico. Revista Jus Navigandi. 2003. 8(63). Disponível: https://jus.com.br/artigos/3809/o-consentimento-informado-e-aresponsabilidade-civil-do-medico

13. Godoy MF, Ferreira HRA, Pria OAFD. Avaliação do conhecimento da ética médica dos graduandos de medicina. Rev. bras. educ. med. 2014. 38(1):31-37. DOI: http://dx.doi.org/10.1590/S0100$\underline{5022014000100005}$

14. Beauchamp TL, Childress JF. Principles of Biomedical Ethics. 4ed. New York: Oxford University Press, 1994.

15. Fadare JO, Desalu OO, Jemilohun AC, Babatunde AO. Knowledge of medical ethics among Nigerian medical doctors. Niger Med J. 2012. 53:226-30. DOI: 10.4103/0300-1652.107600, https://doi.org/10.4103/0300-1652.107600.

16. Shiraz B. et al. Medical ethics in surgical wards: knowledge, attitude and practice of surgical team members in Karachi. Indian J Med Ethics. 2005. 2(3):94-96. DOI: 10.20529/IJME.2005.048, https://doi.org/10.20529/IJME.2005.048.

17. Brogen AS, Rajkumari B, Laishram J, Joy A. Knowledge and attitudes of doctors on medical ethics in a teaching hospital, Manipur. Indian J Med Ethics. 2009. 6:194-7.DOI: 10.20529/IJME.2009.066, https://doi.org/10.20529/IJME.2009.066. 